\title{
DYNAMIC RESPONSE OF A TRUNK STRUCTURE BUILDING TO MULTIPLE TRANSIENT LOADINGS
}

The paper provides information concerning the dynamic response of building structures exposed to paraseismic loadings. Dynamic loadings can arise inside buildings or can be transmitted to buildings through subsoil, causing vibrations of structures. To carry out a dynamic diagnostics of existing buildings, it is necessary to take measurements of vibration parameters directly from the investigated structure. The paper presents some examples of such investigations, as well as a comparison of the obtained results and calculations with standard dynamic characteristics of existing buildings.

Key words: structure, dynamics, paraseismic loading

\section{Introduction}

Building structures, during many years of operation life, are subject to various dynamic influences, coming from sources located outside the building (for example - street traffic, construction machines' activities) as well as those inside the object (air conditioning and ventilation equipment, personal and cargo lifts, other machines and equipment, installed in the object under consideration). In accordance with the valid law (Art. 62 of the Building Law [1]) users are obliged to carry out, at least once every five years, basic periodical checks aimed at the evaluation of the technical state and usability of the building, related to the efficiency of the whole structure under conditions of the existing and planned influences. Such checking procedure should deliver an answer as regarding the possibility of the object's further use in a defined operation life and present guidelines concerning repairs, operation and maintenance limitations and recommendations for the future.

Technical diagnostics encompasses all influences, including dynamic ones, which are main factors [2] affecting the conclusions' correctness. An excessively high level of dynamic influences leads to a premature wear of individual elements of buildings' structure. Characteristics of dynamic loads as defined by their course in time are considered, mostly, at the point of their affecting the structure or at the point of where they are received by the structure's element are.

Investigations of dynamic influences affecting buildings and construction structures are often closely linked with practical difficulties resulting from stochasticity of the process observed. They occur not in defined and repeatable laboratory conditions but, in the natural environment, in a situation when vibrations sources are of a non-determined character. Such a situation makes it necessary to measure vibrations within the building being diagnosed, in order to statistically process the results and to interpret them professionally.
In each individual case, dynamic measurements have to be carried out in conditions representative of the effects considered (for example, one must not limit the number of dynamic loads' sources occurring in a normal operation and maintenance conditions). In further part of the paper results of investigations nonstationary multiple transient dynamic influences affecting the work of reinforced concrete and steel structure of an administration and office building will be presented.

\section{Description of dynamic investigations}

The measurements of dynamic loadings concerning an existing multi-storey building of two- shaft structure (towers "A" and "B") situated in Warsaw at a distance of about $150 \mathrm{~m}$ to the North - West from the intersection of Powązkowska Street and Zygmunt Krasiński Street. The aim of the measurements was to determine causes of falling off the walls' façade plates, made of architectural glass. Recently, in the building's vicinity, the roadway of Powązkowska Street has been widened and a multi-storey apartment block has been built. In the aftermath of these, the nearby traffic increased over that determined in the technical design. During the realisation of measurements, the following multiple transient loadings were affecting the structure:

- loads acting directly on the considered structure, the source of which was located inside the building (new lifts, air condition appliances, electric motors).

- loads being transferred upon the building's structure through subsoil and air (street traffic, wind).

The measurements and diagnostic analysis were carried out, based on recommendations contained in valid standards regulations and those found in literature concerning building structures diagnostics.

\footnotetext{
* Tadeusz Kasprowicz, Leopold Kruszka, Ryszard Rekucki

Wojskowa Akademia Techniczna, ul. Kaliskiego 2, skr. poczt. 50, PL-00-908 Warszawa 49, Poland, E-mail: tkasprowicz@wat.edu.pl
} 


\subsection{Description of diagnosed object}

The building in 46/50 Powązkowska Street, undergoing a periodical technical evaluation constitutes an objects' system consisting of two buildings (towers "A" and "B"), nine and ten floors high, connected by a linking member, and the ground floor part of height up to $8.70 \mathrm{~m}$. Both towers are a trunk construction. Demonstrative outlines of objects considered are shown in Fig. 1.

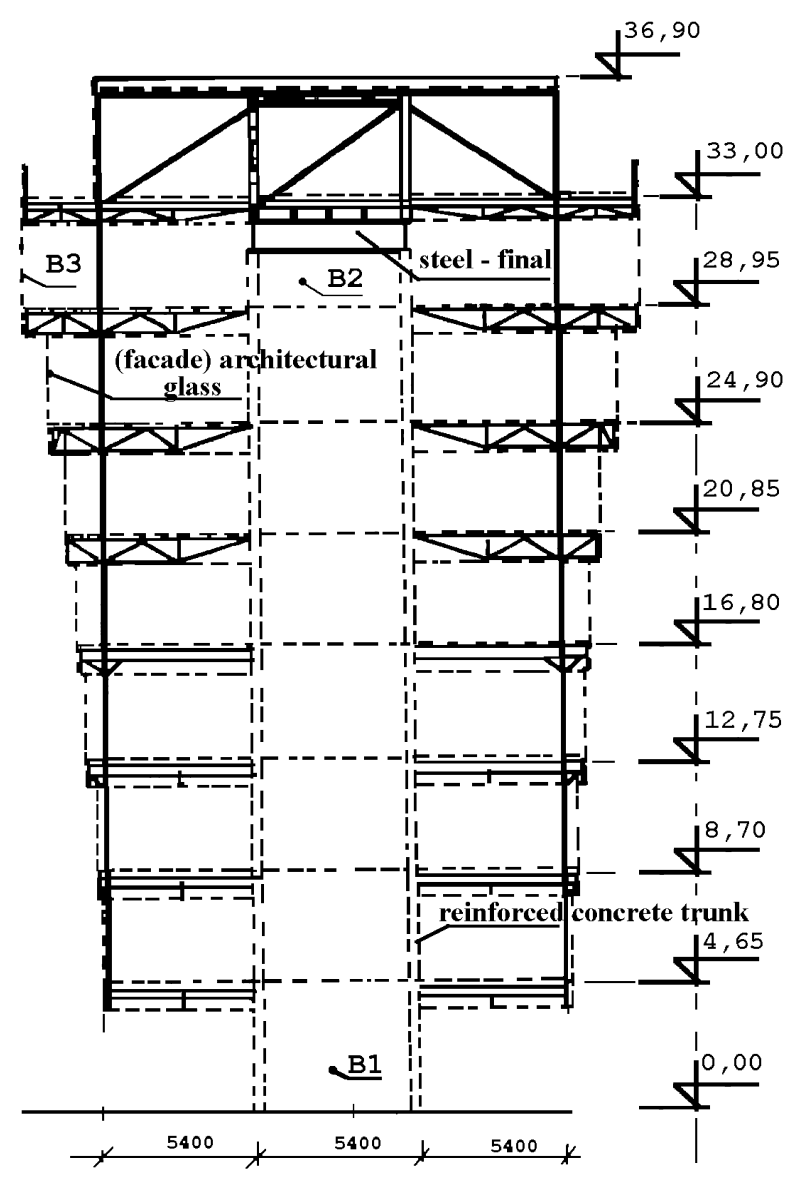

Fig. 1. Demonstrative outlines of diagnosed object - tower " $B$ " with locations of measurements points: $B_{1}, B_{2}$ and $B_{3}$.

The main carrying elements of the buildings' structure are reinforced concrete trunks, of axial dimensions, in a horizontal projection of $5.40 \mathrm{~m}$ by $5.40 \mathrm{~m}$ and of the wall $30 \mathrm{~cm}$ thick. The height of tower "A" is $41.45 \mathrm{~m}$ and that of tower "B" - $38.10 \mathrm{~m}$. Steel cantilever cornices were mounted on the upper edge of the reinforced concrete trunks. Steel vertical hangers supporting the steel structures of the beams of individual floors were attached to the supports' endings. The beams ends are supported directly on the reinforced concrete trunks through the intermediary of brackets welded to marks anchored in the trunks' concrete. Axial dimensions of floors in a projection are $16.2 \mathrm{~m}$ by $16.2 \mathrm{~m}$, they widen upwardly up to the dimensions of $21.5 \mathrm{~m}$ by $21.5 \mathrm{~m}$. Two lift shafts are situated within each of the two trunks. The engine rooms of the lifts found their place on the highest floors (on the eighth and ninth respectively). The inter-storey floors are supported on steel beams of $2 \mathrm{~m}$ spacing on which rolled steel sheets were spread out and a reinforced concrete plate, minimum $5 \mathrm{~cm}$ thick was placed. The height of an individual floor is $4.05 \mathrm{~m}$, and that of floor structure is $1.05 \mathrm{~m}$.

The structure of façade walls was mounted on individual floors' edges. Window elements, $150 \mathrm{~cm}$ wide, are separated by $30 \mathrm{~cm}$ wide full elements of the façade walls. The inner parts of those walls are made of "Baletice" - type plates. The outside of the structure is covered with $3 \mathrm{~mm}$ thick architectural glass and the inside by asbestos-cement plates. Schematic pictures of façade walls are shown in Fig. 2.

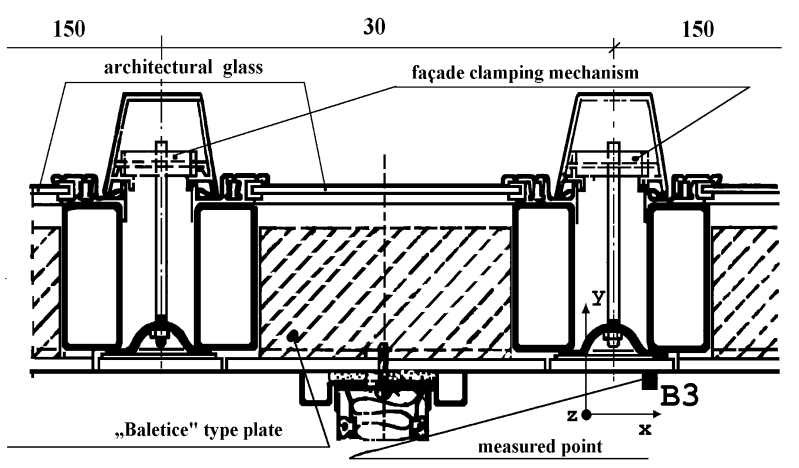

Fig. 2. Façade wall cross-section and location of measurement point B3.

The linking member structure is situated between two towers, which are expansion - joined with them in both planes. The structure is of the same height as tower "B". The design structure of the linking member is based on a system of steel columns (pillars) anchored in the foundations. As working action of the linking member itself has no direct effect on the behavior of the structural elements of façade walls, no dynamic investigations on the linking member pillars were conducted.

The structures of one-floor high extension buildings are separate objects and were omitted in the diagnostics of the towers' structures.

\subsection{Object's foundation in subsoil}

The soil in the immediate foundation area of individual buildings of the structure's aggregate in 46/50 Powązkowska Street belongs to weak subsoils. For this reason, the separate foundation plates of the towers "A" and "B", and the linking member were founded on reinforced concrete pillars. Directly on the foundation plate, the reinforced concrete trunks of the towers were founded. The structure of the tower's foundation is shown in Fig. 3. Such a type of foundation results in a very low turning of the plate as well as in the structure's resistance to dynamic loads transferred through the subsoil. 


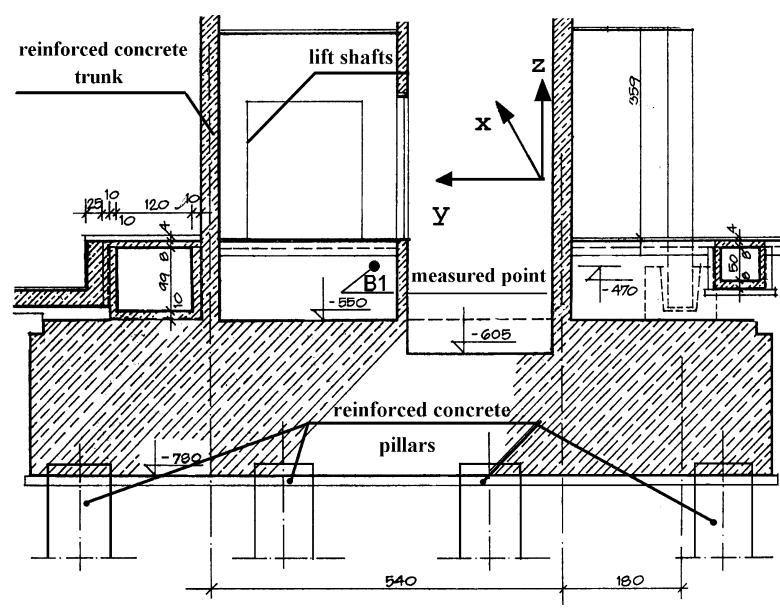

Fig. 3. Structure of tower's foundation and location of measurement point B1.

\subsection{Characteristics of equipment and of measurement procedure}

For the evaluation of dynamic effects, it is necessary to objectively determine their level through a direct measurement, realised at the construction site. In the system under consideration, vibrations have a multiple, transient character, close to random ones. The diagnostic procedure in this case consists in measuring realtime vibrations and then, statistically processing the obtained results. According to the PN-85/B - 02170 standard [5], a measurement line has to comprise measuring gauges (transformers), signal formation system, and a recording or displaying device.

Based on standards-related requirements and those concerning the structure being diagnosed, changes in the time of vibration acceleration values in selected points, characteristic for the building's design structure, have been adopted as measurement parameters. To this end, the accelerometers (PCB Piezotronics) have the following measurement characteristics:

1. Model 393B12 - sensitivity about $982 \mathrm{mV} / \mathrm{ms}^{-2}$, measurements range from $8 \cdot 10^{-5} \mathrm{~ms}-2$ to $4.9 \mathrm{~ms}^{-2}$, measured frequency range $0.1-1000 \mathrm{~Hz}$.

2. Model 393A03 - sensitivity about $100 \mathrm{mV} / \mathrm{ms}^{-2}$, measurements range from $8 \cdot 10^{-5} \mathrm{~ms}^{-2}$ to $49 \mathrm{~ms}^{-2}$, measured frequency range $0.1-1000 \mathrm{~Hz}$, were used.

These parameters fulfil the requirements defined in the relevant standard and the accelerometers also posses a currently valid certificate for the agreement with the ISO 10012 - 1 and military standards of MIL-STD 45662A. The indication accuracy of the whole measuring system used in the testing does not exceed $2 \%$. The diagram of the measuring system is shown in Fig. 4.

Signal from measuring transformers, fixed to the standardised measurements cube, along mutually perpendicular axes $x, y, z$, was transmitted to an 8-channel M482A18 amplifier (PCB Piezotronics), with amplification capabilities of 1, 10, 100 - simultaneously from two measurement points. The measurements cube, with its sensors, during vibration observations, was permanently fixed to the building's structure with the help of a magnetic connector and a specially designed steel plate fixed to structure's material in the site selected for observations of dynamic responses.

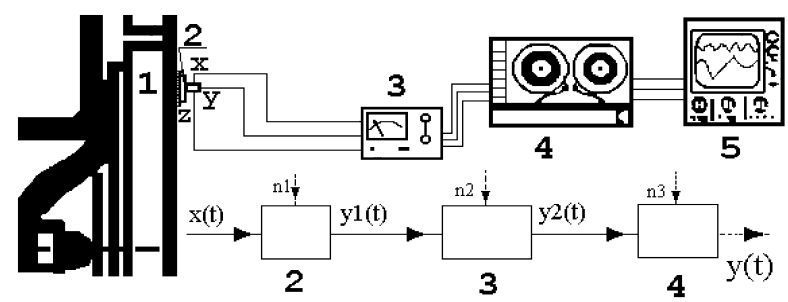

Fig. 4. Diagram of the measurement set for recording vibrations of building's structural elements: 1 - panel wall - investigated element, 2 - piezoelectric accelerometers, 3 - multi-channel amplificatory of the loading and signal formation, 4 - multi-channel magnetic recorder 5 - multi-channel digital control oscilloscope.

Following its appropriate amplification, an analogue signal was recorded on the BASF E-240 magnetic tape of the professional 24-channel V-STORE recorder (RACAL). The recording was conducted randomly (in conditions of the building's use) at two points, with transformers fixed along $x, y, z$-axes. In each case, the measurement of three 5-minutes time slots was made. For current observation of the vibration level and for proper determination of amplifications necessary on individual constitutive members of the measurements' lines a 4-channel digital oscilloscope of the 0 - $8 \mathrm{GSa} / \mathrm{s}$ measurements band was used. The oscilloscope's software makes it also possible to speedily decompose the signal observed in the domain of time into the signal imaged in the domain of frequencies, which enables a correction of the measurement parameters.

\subsection{Distribution of measuring gauges during experiments}

Following the analysis of the static system of the relevant structure, and the attempt of paraseismic diagnosis (determining the causes of falling-off of the façade glass plates during building's maintenance) while taking into account technical conditions for installing accelerometers on the object's load-bearing structure it was decided that the recording of acceleration values in the function of time would be conducted on the tower's trunks, in the technical rooms on the lower ground floor level, that of the seventh floor and on the façade wall structure of the Powązkowska Street side, at a point distanced $5.50 \mathrm{~m}$ (tower "A") and $6.50 \mathrm{~m}$ (tower "B") from the building's corner.

During the first experiment, measuring gauges were positioned in the following places: point A1 - on the trunk of tower "A" on a lower ground-floor level, at a point $80 \mathrm{~cm}$ above the floor level (measurement relative to $x, y$ and $z$ axes) and adequately point $\mathrm{B} 1$ (Figs 1 and 3) - on the trunk of tower "B" on a lower ground-floor level, at a point $80 \mathrm{~cm}$ above the floor level (measurement relative 
to $x, y$ and $z$ axes). In the second experiment, measuring gauges were located at the following points: A2 - on the trunk of tower "A", on the seventh floor level, at a the point $80 \mathrm{~cm}$ above the floor level (measurement relative to $x, y$ and $z$ axes), A3 - on the façade wall structure, on the same floor in a corner room from the Powązkowska Street side, at the point $120 \mathrm{~cm}$ above the floor level (measurement relative to $x, y$ and $z$ axes).

During the third experiment measuring gauges were positioned in the following points: B2 (Fig. 1) on the trunk of tower "B" on the seventh floor level at a point $80 \mathrm{~cm}$ above the floor level (measurement relative to $x, y$ and $z$ axes), B3 on the façade wall structure (Figs. 1 and 2), on the same floor, in a corner room from the Powązowska Street side, at a point $120 \mathrm{~cm}$ above the floor level (measurement relative to $x, y$ and $z$ axes).

\section{Analysis of measurement results.}

\subsection{Apparatus and software used in the analysis of measurement signals}

According to the PN-85/B-02170 Polish Standard, a non-direct method of measurements had to be adopted, consisting in analogue recording of the vibrations' acceleration signal on a magnetic tape and a following spectral analysis of the signal recorded in laboratory conditions.

Quality analyses were conducted with the help of the "Vibrations" software package in the STYST environment, and the statistical evaluations, i. e. correlation and regression coefficients, with the help of SYSTAT software - Fig. 5.

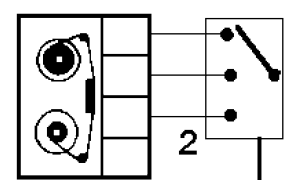

1

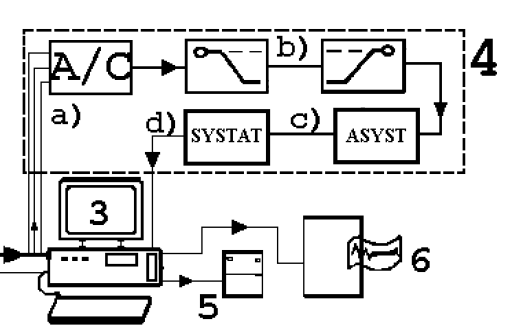

Fig. 5. Diagram of measurement set for measurement data analysis and sensing the vibrations of the building's structural elements:

1 - multi-channel magnetic recorder, 2 - channel selector, 3 - computer,

4 - computer module for digitising and an analysis of measurement signals, ( $a$ - analogue-to-digital converter , $b$ - digital low-and-high pass filter, c-ASYST software for analysis and gathering, $d$-SYSTAT software for statistical analysis , 5-floppy or compact disk, 6 - printer or plotter, 7 - oscilloscope.

The quantification and sampling of the analogue signal into the digital one, used in the analyses, was conducted on a digital four-channel oscilloscope with the frequencies of 250 samples per second and 1000 samples per second, with generated at the level of 0.8 of the maximal observed value being measured.
Discrete vibration runs were recorded, in the function of time, being of a 1024 points' length, which constitutes 4096 ms for 250 samples per second, and $1024 \mathrm{~ms}$ at the 1000 samples per second of sampling.

Data series from individual measurement points, registered separately from $x, y$ and $z$ axes were subjected to initial processing by conducting a scale change, depending on the given accelerometer's sensitivity, from signals expressed in volts to those expressed in $\mathrm{ms}^{-2}$.

\subsection{Analysis method of measurement signals}

The investigated building's structure is affected by vibrations, which are generated by street traffic and by the permanently used building's equipment. The vibrations from the street traffic are transferred to the building's structure by subsoil. The vibrations from the building's equipment are passed directly onto the building's structure. The characteristics of the amplitude and frequency of vibrations undergo continuous changes in time depending on street traffic intensity, the number of personal and cargo lifts in operation, ventilation motors in use, wind strength, air temperature, etc. Generally, they are long-term, recurrent and transient random signals. A theoretical analysis of such a complex loading system and its influence on the building's structure is very complicated and laborious. Fortunately, in order to assess the influence of vibrations on the building structure it is not necessary to describe the course of vibrations in detail. It is sufficient to recognize the course, in a representative period of using the building, as a complex superposition of vibrations caused simultaneously by all sources. In such conditions, vibrations were measured and recorded as analogue signals. The analogue signals were converted into digital ones and then analysed. A series of measurements was carried out on a digital 4-channel oscilloscope at the sampling frequency of 1000 samples per sec generated at 0.8 of the maximal observed measured value. Data sets from particular measurements points, recorded separately for the axes of $x, y, z$ were subjected to initial processing by trans-scaling, depending on given accelerometers sensitivity, from a voltage signal $[\mathrm{V}]$ into an acceleration one $\left[\mathrm{m} / \mathrm{s}^{2}\right]$. Then, each signal was zeroed and averaged.

Typical vibration courses of structural elements of trunk "B" of the examined building occurring relative to the global axis $y$, established during investigations, in the function of time are presented in Fig. 6, the structure of the glass panel wall is shown in Fig. 7.

An increased level of vibrations was observed during passages of personal lifts. On the 7-th floor, vibrations of the trunk structure intensified with a lift cabin approaching the highest floor and during braking. At the same time, a distinct increase of vibration intensity with a tendency hitting the shaft walls was observed in the panel wall structure - see Fig. 7.

In the reinforced concrete trunk's structure, at the B2 measurement point maximal vibrations amplitudes of $-0.01049 \mathrm{~m} / \mathrm{s}^{2}$ 
and $+0.01389 \mathrm{~m} / \mathrm{s}^{2}$ were observed. On the other hand, accordingly, at the B3 measurement point, in the glass structure of the panel wall, vibration amplitudes were $-0.0245 \mathrm{~m} / \mathrm{s}^{2}$ and $+0.02666 \mathrm{~m} / \mathrm{s}^{2}$.

\section{Vibration damage assessment}

All the methods known nowadays concerning the assessment of vibration induced damage can be divided, according to the adopted parameter, depending on velocity, acceleration, and energy. An approximate assessment was carried out with the use of the condition for the acceleration amplitude value of horizontal subsoil movement at the structure's foundation site as:

$$
a_{p}<0.005 g<0.049 \mathrm{~ms}^{-2}
$$

where:

$a_{p}$ - horizontal movement acceleration amplitude,

$g$ - earth gravitation acceleration.

For such assessment reliable are vibration acceleration values measured in the measurement points $\mathrm{A} 1$ and $\mathrm{B} 1$, which were located on the reinforced structure of the tower trunks, i. e. at the basic

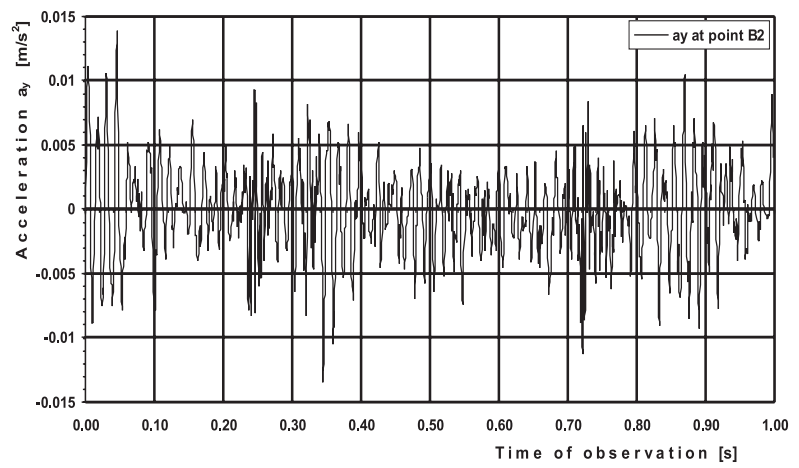

Fig. 6. Vibrations course relative the axis $y$ at the $B 2$ measurement point - reinforced trunk at the 7th floor.

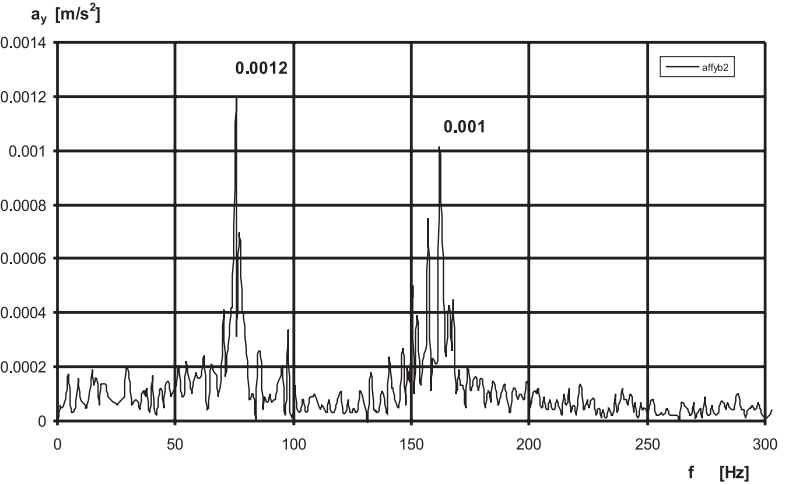

Fig. 7. Amplitudes acceleration spectrum relative the $y$-axis at the B2 measurement point - 7th floor reinforced concrete trunk. carrying structure element of the diagnosed buildings, and at the surrounding ground level, according to the PN-85/B-02170 standard. Maximal values of the acceleration amplitude in the considered points are about $50 \%$ of the admissible value as defined by relationship (1). Moreover, the building in question is situated at the distance of over $15 \mathrm{~m}$ from the traffic-loaded road axis and, according to the PN-85/B-02170 Standard, the effects of vibrations transmitted by the subsoil can be neglected in the dynamic calculations.

Velocity values as determined in a narrow-band analysis for the measurement points: A2, B2, A3 and B3, were used in the assessment of the maintenance-related vibrations' effect on the façade walls. The current Polish standards do not provide any criterion for the diagnostic procedure for such cases. Based on the analysis found in literature and on the author's own research concerning affecting the design structure of façade walls, especially that of façade plate made of $3 \mathrm{~cm}$ - thick architectural glass of the dimensions: $150 \mathrm{~cm} \times 405 \mathrm{~cm}$ and $100 \mathrm{~cm} \times 405 \mathrm{~cm}$ a criterion of velocity was adopted.

The design structure of façade walls is supported on individual storeys' floor edges. Additionally, the architectural glass plates

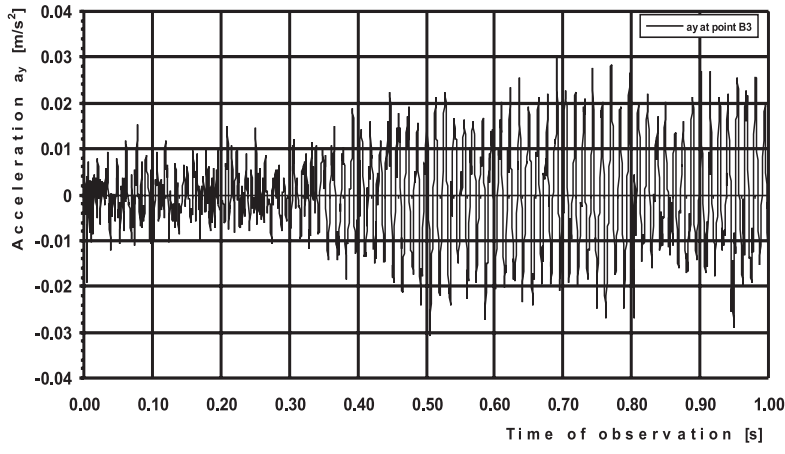

Fig. 8. Vibrations course relative axis $y$ at the B3 measurements point - panel wall.

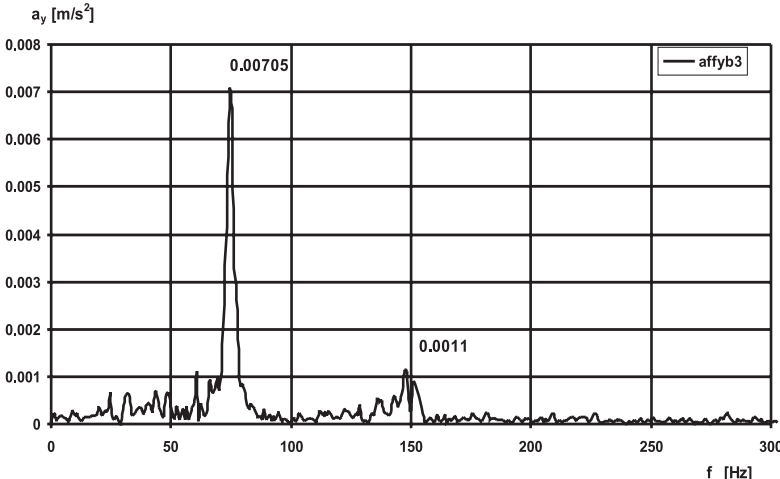

Fig. 9. Amplitude acceleration spectrum relative the y-axis at the B3 measurement point on panel wall. 


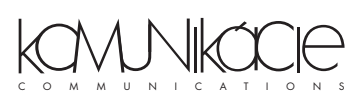

are fixed in place with aluminium clamps and a clamping mechanism - see Fig. 2. Storey floors, on the other hand, are connected with the given tower's reinforced concrete trunks with the help of grid beams. Such a design solution suggests that the velocity parameters determined in the points: A2, A3, B1 and B3 can be used to determine the level of usage-related vibrations affecting the component elements of the façade walls. According to the adopted criterion and taking into consideration the data from the PN85/B-02170 standard for devices especially sensitive to dynamic effects, i. e. first class of sensitivity, the admissible effective value of one-directional velocity is $0.1 \mathrm{mms}^{-1}$.

Maximum effective velocity values were observed at the measurement points fixed on the façade walls structures:

- A3 $x$-axis: $0.02953 \mathrm{mms}^{-1}$ at the frequency of $78.12 \mathrm{~Hz}$,

- A3 $y$-axis: $0.02372 \mathrm{mms}^{-1}$ at the frequency of $23.44 \mathrm{~Hz}$,

- B3 $x$-axis: $0.0322 \mathrm{mms}^{-1}$ at the frequency of $75.19 \mathrm{~Hz}$,

- B3 $y$-axis: $0.01492 \mathrm{mms}^{-1}$ at the frequency of $74.21 \mathrm{~Hz}$,

- B3 z-axis: $0.01642 \mathrm{mms}^{-1}$ at the frequency of $75.19 \mathrm{~Hz}$.

Moreover, at the frequencies lower than $10 \mathrm{~Hz}$ in the points:

- A3 x-axis: $0.01307 \mathrm{mms}^{-1}$ at the frequency of $9.76 \mathrm{~Hz}$,

- A3 $y$-axis: $0.01238 \mathrm{mms}^{-1}$ at the frequency of $9.76 \mathrm{~Hz}$,

- B3 $x$-axis: $0.01038 \mathrm{mms}^{-1}$ at the frequency of $8.78 \mathrm{~Hz}$,

- B3 $z$-axis: $0.04754 \mathrm{mms}^{-1}$ at the frequency of $8.78 \mathrm{~Hz}$.

\section{Conclusions}

The analysis of spectral characteristics of amplitude accelerations in the points of A2, A3, B2 and B3 - see Fig. 4, has shown the existence of vibrations caused by the passage of personal lifts situated within the towers' trunks through floors and beams onto the structural elements of the façade walls. This phenomenon is especially evident at the frequency ranges of $70-79 \mathrm{~Hz}$ and $140-$ $160 \mathrm{~Hz}$ on the distribution diagrams of the acceleration spectrum for above points. Because of the design of the floors (reinforced concrete plate on zinc covered sheet) and mutual connection of the floors with the façade walls at the measurement points situated on these walls, $6-8$ times increase of vibration level was observed in comparison to the points fixed on the trunks, at the seventh floor level. The velocity peak values within the whole range of the analysed frequencies, i. e. $0-500 \mathrm{~Hz}$ do not exceed the limit value for machines and equipment of very high vibration sensitivity. In the conditions of the measurements realization, peak values of $2.1-9.6$ times lower than the admissible were observed. The level of maintenance-related vibrations in the building has no immediate harmful effect on the component elements of the reinforced concrete and steel structures and the façade walls. The computed frequency of resonance vibrations for architectural glass plate is about $24 \mathrm{~Hz}$ and the experimentally determined vibration parameters are the most intensive within the frequency ranges of $70-80 \mathrm{~Hz}$ and $140-160 \mathrm{~Hz}$, which excludes the development of façade walls resonance and, as a consequence, their falling-off from the main structure.

One should conclude that the maintenance related wear, and the fact that the clamping system on the façade walls structure more than 20 years old, contributed to the falling off of architectural glass plates. The wear of the mounted elements with a simultaneous action of high intensity winds and considerable temperature changes can lead to further cases of the glass plates falling off of the building's façade.

\section{References}

[1] Polish building law: Construction Law - Act from 1994 July 7 (in Polish - Dz. U. z 1996 roku nr 89, poz. 414).

[2] CIESIELSKI, R.: Dynamical diagnosis in building engineering (in Polish), Construction Review (in Polish) 1/1993, pp. 4 - 13.

[3] CIESIELSKI, R., MACIĄG, E.,STYPUŁA, K.: Using of vibrations' spectrum to dynamical diagnosis of buildings (in Polish), Proceedings of the XXXVIII Conference of Civil Engineering Committee, Polish Academy of Sciences, vol. 1, Krynica, 1992.

[4] BEAUCHAMP, K. G.: Signal processing. Using Analog and Digital Techniques, George Allan \& Unwin Ltd., 1973.

[5] POWERS, D. L.: Boundary value problems, Academic Press, 1979.

[6] ASYST, Module 2 Analysis, Asyst software Technologies, 1990.

[7] Polish Standard PN-91/N-01352 "Vibrations. Principles of making measurements at work stations (in Polish)".

[8] Polish Standard PN-88/B-02171 "Assessment of vibrations' influence on people at buildings (in Polish)".

[9] Polish Standard PN-85/B-02170 "Assessment of harmfulness of vibrations transmitted through subsoil to buildings (in Polish)".

[10] Polish Standard PN-80/B-03040 "Machines foundations and bearing structures. Calculations and designing (in Polish)".

[11] German Standard DIN-4150-2-3, 1986, "Erschütterungen im Bauwesen”.

[12] Czechoslovakian Standard ČSN-730036, 1996, "Seismické zatížení staveb".

[13] ISO-IS 10137-1992, "Serviceability of buildings against vibration". 